\title{
A PARTICIPAC̃̃̃ SOCIAL NA SUSTENTABILIDADE DO REASSENTAMENTO DA VILA PRODUTIVA RURAL NEGREIROS RESULTANTE DO PROJETO DA TRANSPOSIÇÃO DO RIO SÃO FRANCISCO
}

\author{
Social participation in the sustainability of resettlement of rural negreiros production village \\ resultant project of the transposition of Rio São Francisco
}

\begin{abstract}
RESUMO
O Projeto da Transposição do Rio São Francisco visa à integração de bacias hidrográficas no nordeste setentrional, como forma de atendimento a 12 (doze) milhões de nordestinos, nos estados de Pernambuco, da Paraíba, do Ceará e do Rio Grande do Norte; região essa que historicamente sofre pela indisponibilidade hídrica. O presente artigo apresenta uma reflexão sobre a importância da participação social como estratégia de desenvolvimento local sustentável, no reassentamento da Vila Produtiva Rural Negreiros, no Projeto da Transposição do Rio São Francisco. A metodologia adotada incluiu a utilização de pesquisa documental a aportes teóricos e a fontes documentais, a observação participante (in loco), e a verificação de conteúdo pertinente, em que se constatou o processo participativo desenvolvido junto às famílias daquela VPR, com vistas à autossustentabilidade. As categorias analisadas foram: a participação social, a educação ambiental e a sustentabilidade para o desenvolvimento local. Foi obtido um Índice de Participação Social que permitiu classificar a participação comunitária durante o desenvolvimento das ações realizadas. Este estudo ratifica a importância da participação na organização social dos atores envolvidos ao longo do processo de reassentamento, mas também, alerta que o processo almejado de desenvolvimento local sustentável, até o momento verificado nessa pesquisa, se encontra distante da realidade atual das famílias, devido principalmente a não efetivação prática do viés produtivo e todo o seu arcabouço, ainda dependente da conclusão do Projeto da Transposição do rio São Francisco.
\end{abstract}

Ramom Campos Bastos da Silva

Instituto Federal de Educação, Ciência e Tecnologia de Pernambuco

agroramom@hotmail.com

Marília Regina Costa Castro Lyra

Instituto Federal de Educação, Ciência e Tecnologia de Pernambuco

mariliarcastro@uol.com.br

Maria Núbia Medeiros de Araújo Frutuoso

Instituto Federal de Educação, Ciência e Tecnologia de Pernambuco

nubiafrutuoso@yahoo.com.br

Recebido em: 18/04/2016. Aprovado em: 13/06/2017

Avaliado pelo sistema double blind review

Avaliador científico: Renato Silvério Campos

DOI: 10.21714/2238-68902017v19n2p096

\begin{abstract}
The São Francisco River Transposition Project aims at the integration of hydrographic basins in the northern Northeast, as a form of service to 12 (twelve) million Northeasterners, in the states of Pernambuco, Paraíba, Ceará and Rio Grande do Norte; A region that historically suffers from water unavailability. The present article presents a on the importance of social participation as a strategy for sustainable local development in the resettlement of VPR Negreiros in the São Francisco River Transposition Project. The methodology adopted included the use of documentary research for theoretical contributions and documentary sources, participant observation (in loco), and verification of pertinent content, in which the participatory process developed with the families of the VPR was verified, with a view to self-sustainability. The categories analyzed were: social participation, environmental education and sustainability for local development. A Social Participation Index was obtained that allowed to classify the community participation during the development of the actions carried out. This study ratifies the importance of participation in the social organization of the actors involved throughout the resettlement process, but also warns that the desired process of sustainable local development, so far verified in this research, is far from the current reality of the families, due to Mainly the practical ineffectiveness of productive bias and its entire framework, still dependent on the conclusion of the São Francisco River Transposition Project.
\end{abstract}

Palavras-chaves: Integração de Bacias, Semiárido, Desenvolvimento Rural.

Keywords: Integration basins, Semi-arid, Rural development. 


\section{INTRODUÇÃO}

Este artigo traz à discussão, a problemática que envolve o estabelecimento dos reassentamentos rurais, cada vez mais crescentes em todo o Brasil, nas últimas décadas, e que em sua maioria não conseguem ter sucesso quanto ao desenvolvimento local sustentável, preconizado em seus planejamentos iniciais. Destaque-se, nesse escopo, a necessidade de se verificar a importância do processo da participação social nessas comunidades rurais formadas, e que ultimamente vem ganhando espaço na sociedade em geral, sobretudo entre estudiosos e profissionais afins

O objeto do estudo é inferir sobre a importância dessa participação familiar nas interrelações sociais, econômicas e ambientais, com vistas ao desenvolvimento local sustentável, ao longo do processo de reassentamento de 26 famílias residentes em áreas afetadas pelas obras de implantação do Projeto da Transposição do rio São Francisco, também denominado pelo Governo Federal, de Projeto de Integração do Rio São Francisco com as Bacias Hidrográficas do Nordeste Setentrional (PISF).

A metodologia adotada incluiu a utilização de pesquisa documental a aportes teóricos e a fontes documentais, a observação participante (in loco), e a verificação de conteúdo pertinente, em que se buscou constatar o processo participativo desenvolvido e a sua importância junto às famílias daquela Vila Produtiva Rural (VPR), com vistas à autossustentabilidade.

\section{REVISÃO DE LITERATURA}

\subsection{A participação social}

A vida em sociedade é uma exigência da natureza e da condição do homem que sempre necessitou de seus semelhantes para sobreviver, perpetuar a espécie e também na busca de sua realização pessoal, através do estabelecimento de vínculos de organização social.

Destaque-se, não faz muito tempo, que no meio rural por todo o Brasil, surgia o desenvolvimento do cooperativismo rural, visto como mecanismo de modernização da agricultura. No final da década de 60, começo dos anos 70, o cooperativismo rural aponta como estratégia de crescimento econômico e instrumento de mudança social.

(...) É na base dos movimentos sociais que são construídos novos espaços de participação organizados por novas práticas que se colocam entre o público e o privado como espaços institucionalizados de consulta, debate, expressão e deliberação sobre questões fundamentais para a sociedade, onde os sujeitos podem expressar suas necessidades e aspirações, potencializando a ação participativa e buscando a ampla democratização do Estado (PINTO, 2004, p.60).

A teoria da democracia participativa extrapola a esfera do interesse individual, alcançando os interesses coletivos e tornando as decisões políticas mais justas e democráticas. Ao passar pela manifestação pública dos interesses da população, as decisões políticas tendem a alcançar maior eficiência e legitimidade (AVRITZER, 2002).

Para esse autor, no Brasil, o ideal da "democracia participativa" vem se fortalecendo com o processo de abertura política, iniciado após o fim do período militar, entretanto, a participação social na vida política brasileira ainda dá os primeiros passos. Corrobora o autor que, a participação social nas políticas públicas contribui, de um modo geral, para melhorar o uso e a distribuição do poder político, mas que para isso, a teoria da democracia supõe cidadãos interessados, informados e capazes de participar da vida política.

No entanto, em inúmeros casos, essa participação social encontra-se à mercê do poder local e até mesmo regional, onde a representação da sociedade civil é facilmente cooptada por uma estrutura clientelista e tutelar; o que corrobora a afirmação de que é necessário ultrapassar somente a institucionalização das novas esferas participativas, é preciso torná-las espaços que interfiram efetivamente no processo de discussão e tomada de decisão.

\subsection{A educação ambiental}

Sobre a constatação dos fatos históricos, e considerando o atual cenário de descuido com os elementos naturais e com a vida, acenou Loureiro (2003), que para se alcançar mudanças significativas em relação ao quadro de crise ambiental em que vivemos, a Educação Ambiental se define como elemento estratégico na formação da ampla consciência crítica das relações sociais que situam a inserção humana na natureza.

Apresenta Gadotti (2007), que a educação para o desenvolvimento sustentável se caracteriza por ser mais do que uma base de conhecimentos relacionados com o meio ambiente, com a economia e com a sociedade; se ocupa, segundo o autor, da aprendizagem de atitudes, perspectivas e valores que orientam e impulsionam as pessoas a buscarem uma vida mais sustentável. Trata-se, portanto de uma educação voltada para se ter uma consciência dessa responsabilidade ambiental. A esse respeito, corrobora 
que devemos ter uma relação mais sustentável tanto com as pessoas como também com o meio ambiente, em vez de "nos consideramos senhores da terra", devemonos considerar parte dela. Este pensamento também foi ensejado por Boff (2009), ao enfatizar a necessidade de se criar uma nova mentalidade educacional, uma concepção na qual se busque atingir um novo desenvolvimento, um desenvolvimento sustentável.

Para Janke \& Tozoni-Reis (2008) apud Silva (2009), a educação ambiental deve ir além do manejo de instrumentos e técnicas; deve avançar no sentido de pôr em prática ações destinadas a melhorar as relações dos homens entre si e com a natureza, respeitando os limites ecossistêmicos e proporcionando o desenvolvimento com sustentabilidade. Essas ações devem promover a educação ambiental em apoio ao desenvolvimento local e à melhoria da qualidade de vida como um todo, precisa, portanto, estar inserida em um processo permanente de aprendizagem e de aplicação prática do conhecimento, considerando as várias interações entre os recursos naturais e o homem, e a sua convivência de forma eficaz e harmoniosa.

Assim, a educação ambiental se constitui em uma nova forma de se pensar os problemas ambientais, propondo-se atingir todos os cidadãos, através de um processo pedagógico participativo permanente, procurando incutir uma consciência crítica sobre a problemática ambiental. Para tanto é interessante buscar uma educação que se propõe a fomentar processos continuados que possibilitem o respeito à diversidade biológica, cultural, étnica, juntamente com o fortalecimento da resistência da sociedade a um modelo devastador das relações de seres humanos entre si e destes com o meio ambiente (BRASIL, 2007).

(...) Educação ambiental é uma coisa mais séria do que geralmente tem sido apresentada em nosso meio. É um apelo à seriedade do conhecimento. É uma busca de propostas corretas de aplicação de ciências. Uma "coisa" que se identifica com um processo que envolve um vigoroso esforço de recuperação de realidades, nada simples. Uma ação talvez utópica destinada a reformular comportamentos humanos e recriar valores perdidos ou jamais alcançados. Um esforço permanente na reflexão sobre o destino do homem. [...] um processo de educação que garante um compromisso com o futuro, envolvendo uma nova filosofia de vida e um novo ideário comportamental, tanto em âmbito individual, quanto em escala coletiva (AB'SABER, 1993, p.20).

Neste processo, a educação ambiental é fundamental para a construção do desenvolvimento sob uma ótica sustentável, que segundo o Relatório de Brundtland ${ }^{1}$, apud Amâncio et al.(2001), aborda a responsabilidade comum entre as vertentes: crescimento econômico, equidade social e equilíbrio ecológico, fatores esses primordiais para a edificação de uma sociedade com melhores condições de vida e de sobrevivência.

Esta passagem da construção da racionalidade capitalista para a construção de uma racionalidade ambiental, segundo Leff (2011), se depara no confronto de interesses opostos e pela conciliação de objetivos comuns de diversos atores sociais; em que o modelo capitalista diverge do pensamento ambientalista atual de preservação e conservação ambiental, de modo que esta racionalidade ambiental incorpora um conjunto de valores e critérios que não podem ser avaliados em termos do modelo de racionalidade econômica.

\subsection{A sustentabilidade para o desenvolvimento local}

Pode-se afirmar de maneira abrangente, que o desenvolvimento sustentável refere-se a um processo no qual as políticas econômicas, comerciais, energéticas, agrícolas e industriais são organizadas para produção de um desenvolvimento eficaz com melhores condições de saúde e educação e principalmente o planejamento e gerência dos recursos naturais para não prejudicar as futuras gerações com cargas negativas geradas da exploração excessiva dos recursos naturais (SILVA JÚNIOR, 2008).

[...] desenvolvimento sustentável é um processo de transformação no qual a exploração dos recursos, a direção dos investimentos, a orientação do desenvolvimento tecnológico e a mudança institucional se harmonizam e reforça o potencial presente e futuro, a fim de atender às necessidades e aspirações futuras. [...] é aquele que atende às necessidades do presente sem comprometer a possibilidade de as gerações futuras atenderem as suas próprias necessidades. (RELATÓRIO NOSSO FUTURO COMUM, 1988, p. 46).

Divulga o IBGE (2011), que os princípios do desenvolvimento sustentável estão referendados na base da Agenda 21, documento aprovado por mais de 180 países durante a realização da Conferência das Nações Unidas sobre Meio Ambiente e Desenvolvimento, realizada no Rio de Janeiro em 1992.

As ideias ali contidas foram assimiladas pelas organizações do sistema das Nações Unidas e diversas

${ }^{1}$ BRUNDTLAN, Comissão. "Comissão Mundial sobre Meio Ambiente e Desenvolvimento: o nosso futuro comum. Universidade de Oxford. Nova lorque, 1987. Disponível em: http://eubios.info/BetCD/Bt14.doc 
organizações internacionais, e desde então, têm sido progressivamente incorporadas às agendas de numerosos países. Trata-se de um novo paradigma para abordar um velho desafio: o desenvolvimento. Nesta nova ótica, a noção de desenvolvimento, por muito tempo identificado ao progresso econômico, extrapola o domínio da economia através da sua integração com as dimensões social, ambiental e institucional, apoiando-se em novos paradigmas.

\section{PROCEDIMENTOS METODOLÓGICOS}

\subsection{Caracterização da Vila Produtiva Rural Negreiros}

A população analisada se refere a 26 famílias que foram reassentadas na Vila Produtiva Rural Negreiros (VPR NEGREIROS), no ano de 2010. O estudo utilizou pesquisas realizadas pela equipe técnica do Ministério da integração Nacional, antes da transferência das famílias, em 2009, e após a transferência, em 2015. Ao final, apresentam-se os resultados da avaliação do grau de satisfação das famílias nesse processo de reinserção socioambiental naquela VPR.

Em seu arranjo, a VPR Negreiros apresenta as infraestruturas constantes dispostas em setores, a saber:

a) Setor Residencial

- Lotes residenciais: 26 lotes residenciais de 0,5 hectares cada um.

- Casa: Com área construída de 98,70 m²

- Lotes de expansão: 26 lotes de expansão

- Rede Elétrica

- Sede da Associação

- Área de Lazer: Constituída por 01 campo de futebol e 01 quadra poliesportiva

- Escola

- Posto Médico

- Sistema de Abastecimento de Água com reservatório elevado e estação de tratamento de água compacta e rede de distribuição para todas as casas

- Esgotamento Sanitário feito por sistemas individuais com fossa e vala de infiltração

- Cercamento do Perímetro da VPR

- Estradas Internas

O setor denominado de Núcleo Habitacional, detalhado na Figura 1, engloba as residências e a Escola.

b) Setor Produtivo

O setor produtivo é constituído por duas áreas, sendo uma destinada à agricultura de sequeiro e outra à agricultura irrigada. Os lotes de sequeiro possuem área média individual de 5,2 ha e os lotes irrigáveis apresentam área de 1,00 ha, sendo estes com os sistemas de irrigação a serem implantados pelo MINISTÉRIO DA INTEGRAÇÃO NACIONAL (MIN).

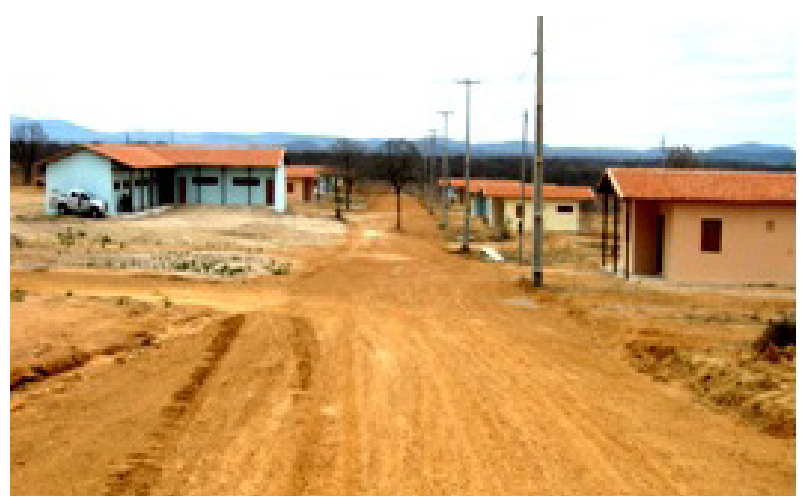

FIGURA 1: Núcleo Habitacional da VPR Negreiros Fonte: Acervo do Autor, 2015

c) Área de Uso Sustentável

A área de uso sustentável é destinada à instalação de infraestrutura coletiva de apoio a produção.

d) Áreas Protegidas

- Área de Reserva Legal: Aárea de RL (126,71 ha) da VPR Negreiros está em conformidade com a Lei No 12.651/12, no Art. 12, que define ser de no mínimo 20\% (vinte por cento) da área total do imóvel.

- Área de Preservação Permanente - APP: Aárea da VPR Negreiros possui um total de 148,66 hectares.

Os dados apresentados foram obtidos a partir de pesquisa documental a questionários socioeconômicos, aplicados por equipes técnicas contratadas pelo Ministério da Integração Nacional, às 26 famílias, em momentos distintos, antes e depois do reassentamento à VPR Negreiros. As informações foram tabuladas e sua análise inferida de acordo com metodologia análoga às metodologias desenvolvidas em estudos realizados por Albuquerque (2002) e também por Carvalho (2009). Esses autores fizeram uso de índices específicos, formados a partir dos indicadores ou atributos analisados, em que foram dados pesos de 1 a 4, de acordo com o nível de resposta aferida, chegando-se a um coeficiente de rendimento, expresso em percentual numa escala de $0 \%$ a $100 \%$, sendo a proximidade de 0 implicando em níveis de Insustentabilidade e próximo a $100 \%$ para os níveis de Sustentabilidade.

De acordo com Meirelles (2014), em projetos sociais os indicadores servem como parâmetros para 
detalhar em que medida os objetivos de um projeto foram alcançados no universo do que especificamente se analisa, em seu devido tempo; e que os mesmos buscam expressar aspectos da realidade sob uma forma de mensuração possível; o que não é trivial por abordar um processo complexo, como no caso das questões sociais, em que indicadores sociais que mostrem a participação social se faz importante.

Seguindo esse raciocínio, e referenciando-se metodologias concernentes a esse tipo de análise, identificadas na literatura recente (LOPES JÚNIOR, 2015; MEIRELLES, 2014; CARVALHO, 2009; ALBUQUERQUE, 2002), adotou-se essa mesma conceituação para gerar no caso dessa pesquisa, o Índice de Participação Social.

O IPS foi utilizado para a avaliação da participação social das famílias no processo de reinserção socioeconômico e ambiental, durante o reassentamento à VPR Negreiros, calculado por meio da fórmula:

$\frac{\mathrm{IPS}=4(\% \mathrm{O})+3(\% \mathrm{~B})+2(\% \mathrm{R})+1(\% \mathrm{D})}{\text { NAR }}$

Em que:

IPS: Índice de participação social

NAR: número de alternativas de resposta

O: Ótimo

B: Bom

R: Regular

D: Deficiente

Em alguns casos, quando não existia a resposta equivalente ao "Ótimo", o número de alternativas de resposta (NAR), foi calculado com as 3 alternativas restantes. Além disso, para um aproveitamento maior dos questionamentos realizados nos formulários aplicados, adaptou-se às alternativas de respostas à classificação apresentada acima.

Com a finalidade de se construir o entendimento específico voltado para os resultados esperados de cada atributo, adaptou-se à realidade local, de acordo com valores-padrão do Índice de Desenvolvimento Humano, segundo os estudos propostos no Projeto BRA/12/018 - Desenvolvimento de Metodologias de Articulação e Gestão de Políticas Públicas para Promoção da Democracia Participativa, a Tabela 1, na qual esses pesos (coeficientes) foram atribuídos a cada nível de resposta, e geraram o IPS.
TABELA 1 - Qualificação do atributo e descrição correspondente

\begin{tabular}{|c|c|}
\hline $\begin{array}{l}\text { Qualificação } \\
\text { do atributo }\end{array}$ & Descrição \\
\hline 4 & $\begin{array}{l}\text { O atributo analisado apresenta participação } \\
\text { social efetiva e consolidada por meio de } \\
\text { processos regulares e permanentes. }\end{array}$ \\
\hline 3 & $\begin{array}{l}\text { O atributo apresenta ocorrência de } \\
\text { participação social e implementação parcial. } \\
\text { Processo em via de consolidação. }\end{array}$ \\
\hline 2 & $\begin{array}{c}\text { Algum tipo de participação social do atributo } \\
\text { foi estabelecido, mas não de maneira regular } \\
\text { e formal. }\end{array}$ \\
\hline 1 & Não houve participação social significativa \\
\hline
\end{tabular}

Fonte: Elaborado pelo autor (2015)

A partir do nível de participação de cada indicador /atributo avaliado pode-se identificar qual o resultado do IPS, bem como analisar se a Categoria de sua participação no processo de reinserção socioeconômico e ambiental ocorrido durante o reassentamento à VPR Negreiros. Tal índice varia de 0 a $100 \%$ e adota as classificações descritas na Tabela 2.

TABELA 2 - Níveis do índice de participação social (IPS) e suas categorias

\begin{tabular}{cc}
\hline Escala índice de & Categorias \\
participação social (IPS) & Participação consolidada \\
\cline { 2 - 2 } IPS $\geq 90 \%$ & Participação satisfatória \\
$70 \% \leq$ IPS $<90 \%$ & Baixa participação \\
$50 \% \leq$ IPS $<70 \%$ & Participação insuficiente \\
IPS $<50 \%$ &
\end{tabular}

Fonte: Elaborado pelo autor (2015)

Foram verificadas durante o processo, por meio de diagnósticos socioeconômicos, realizados antes e depois da transferência das famílias; o que permitiu o acompanhamento e a evolução das suas condições de vida na VPR NEGREIROS, em que a percepção da mudança na qualidade de vida foi aferida por meio de indicadores perceptíveis por meio de pesquisas de opinião das famílias em seu novo ambiente, em que também foram diagnosticados o seu relacionamento nas dimensões sociais, ambientais e econômicas. A Tabela 3 apresenta alguns desses indicadores e também os meios de aferição correspondentes. 
TABELA 3 - Indicadores de desenvolvimento perceptíveis na VPR Negreiros

\begin{tabular}{cc}
\hline INDICADORES & INSTRUMENTOS DE VERIFICAÇÃO \\
\hline GRAU DE SATISFAÇÃO DAS FAMÍLIAS & PESQUISA DE OPINIÃO POR FICHA DE AVALIAÇÃO \\
INDICE DE QUALIDADE DE VIDA & \\
(Nível de renda, acesso à educação, serviços de saúde e & QUESTIONÁRIO SOCIOAMBIENTAL \\
Paneamento, organização comunitária) & \\
$\mathrm{N}^{\circ}$ DE ASSOCIAÇÕES CRIADAS E FUNCIONANDO & FICHA DE MONITORAMENTO \\
\% DE REASSENTADOS ASSOCIADOS & ATAS E REGISTROS \\
$\mathrm{N}^{\circ}$ DE CAPACITAÇÕES REALIZADAS & REGISTRO DO ASSOCIADO \\
DE CAPACITADOS NAS CAPACITAÇÕES & RELATÓRIOS TÉCNICOS \\
\hline
\end{tabular}

Fonte: Planejamento Estratégico do PBA 8 (BRASIL, 2010). Organizado pelo autor

\section{RESULTADOS E DISCUSSÃO}

\subsection{O Projeto da Transposição do Rio São Francisco}

O rio São Francisco, descoberto em 1502, tem esse título por ser o caminho de ligação do Nordeste com o Sudeste e o Centro-Oeste do Brasil. Desde as suas nascentes, na Serra da Canastra, em Minas Gerais, até a sua foz, na divisa de Sergipe e Alagoas, percorre $2.800 \mathrm{~km}$, dividido em quatro "Regiões Fisiográficas", ou seja, em regiões caracterizadas por uma vasta área do semiárido brasileiro, com definições semelhantes, mas de características próprias e únicas; são elas: O Alto São Francisco, que vai de suas cabeceiras até Pirapora, em Minas Gerais; o Médio, de Pirapora, onde começa o trecho navegável, até Remanso, na Bahia; o Submédio, de Remanso até Paulo Afonso, também na Bahia; e o Baixo, de Paulo Afonso até a foz entre os estados de Sergipe e Alagoas (BRASIL, 2004).

O "Velho Chico", como é chamado, pelos seus ribeirinhos, compreende uma Bacia Hidrográfica de 634 mil km2 e recebe água de 168 afluentes, dos quais 99 são perenes, 90 estão na sua margem direita e 78 na esquerda. Os índices pluviais na bacia do São Francisco variam entre sua nascente e sua foz, tendo uma pluviometria média que vai de 1.900 milímetros na área da Serra da Canastra a 350 milímetros no semiárido nordestino. Ao passo que, os índices relativos à evaporação mudam inversamente $\mathrm{e}$ crescem de acordo com a distância das nascentes, indo de 500 milímetros anuais, na cabeceira, a 2.200 milímetros anuais em Petrolina, PE (BRASIL, 2005).

O Projeto visa à integração de bacias hidrográficas no nordeste setentrional, como forma de atendimento a 12 (doze) milhões de nordestinos, nos estados de Pernambuco, da Paraíba, do Ceará e do Rio Grande do Norte; região essa que historicamente sofre pela indisponibilidade hídrica.

A região semiárida, segundo Ab' Saber (1993), constitui-se de paisagens regidas pela ausência, escassez, e uma alta variabilidade espacial de suas precipitações, em que ocorre também, distribuição concentrada, gerando temporal de chuvas. Complementa o autor, que essas condições climáticas apresentam reflexos na formação da sociedade regional que sobrevive, ainda hoje, principalmente de atividades econômicas ligadas basicamente à agricultura e à pecuária. A paisagem da região, denominada "mata branca", na língua indígena "caatinga", apresenta grande biodiversidade, em que se destacam as espécies endêmicas, ou seja, que só coexistem naquele cenário.

O fato é que a Região Nordeste, possui apenas $3 \%$ da disponibilidade de água e $28 \%$ da população brasileira. A irregularidade na distribuição de recursos hídricos, faz do rio São Francisco o representante de 70\% da oferta hídrica regional. Esse efeito torna-se mais radical, ao analisar-se a desigualdade na distribuição de suas densidades demográficas (cerca de $10 \mathrm{hab} / \mathrm{km}^{2}$ na maior parte da bacia do rio São Francisco e aproximadamente 50 $\mathrm{hab} / \mathrm{km}^{2}$ no Nordeste Setentrional), o que faz com que o Semiárido Brasileiro seja dividido da seguinte forma: Um Semiárido da Bacia do São Francisco, com 2.000 a 10.000 $\mathrm{m}^{3} / \mathrm{hab} /$ ano de água disponível em rio permanente, e outro Semiárido do Nordeste Setentrional, compreendendo parte do estado de Pernambuco e os estados da Paraíba, Rio Grande do Norte e Ceará, com aproximadamente $400 \mathrm{~m}^{3}$ /hab/ano, disponibilizados através de açudes construídos em rios intermitentes e em aquíferos com limitações tanto quanto à qualidade, como à sua quantidade de águas, de acordo com dados do Ministério da Integração Nacional (BRASIL, 2005). 
Sobre o empreendimento em si, os estudos realizados pela Agência Nacional de Águas (ANA, 2005) para o Plano Decenal do rio São Francisco indicaram uma vazão disponível para consumo de $380 \mathrm{~m}^{3} / \mathrm{s}$ até 2013 . Também avaliaram o consumo atual da bacia $\mathrm{em} 91 \mathrm{~m}^{3} / \mathrm{s}$ e estimaram a sua ampliação para um cenário otimista de crescimento da irrigação na bacia para até $195 \mathrm{~m} / \mathrm{s}$ a partir de 2013. A vazão consumida atualmente corresponde a $24 \%$ da vazão disponibilizada para consumo, e a $5 \%$ da vazão garantida na foz $\left(1.850 \mathrm{~m}^{3} / \mathrm{s}\right)$, e a $3,4 \%$ da vazão média do rio $\left(2.700 \mathrm{~m}^{3} / \mathrm{s}\right)$.

O projeto São Francisco envolve a construção de 4 túneis, 14 aquedutos, 9 Estações de Bombeamento e 27 reservatórios, além de recuperar 23 açudes. A transposição visa o abastecimento de água para grandes centros urbanos da região, como: Fortaleza, Juazeiro do Norte, Crato, Mossoró, Campina Grande, e Caruaru, mas também atenderá centenas de pequenas e médias cidades inseridas no semiárido e de áreas do interior do Nordeste, como detalha as Figuras 2 e 3, em que destacam os Eixos de Captação e o Ramal do Agreste, que abrange a região das cidades de Arcoverde e Caruaru (orientação sentido Recife), na malha subsequente ao eixo leste, respectivamente (BRASIL, 2004).

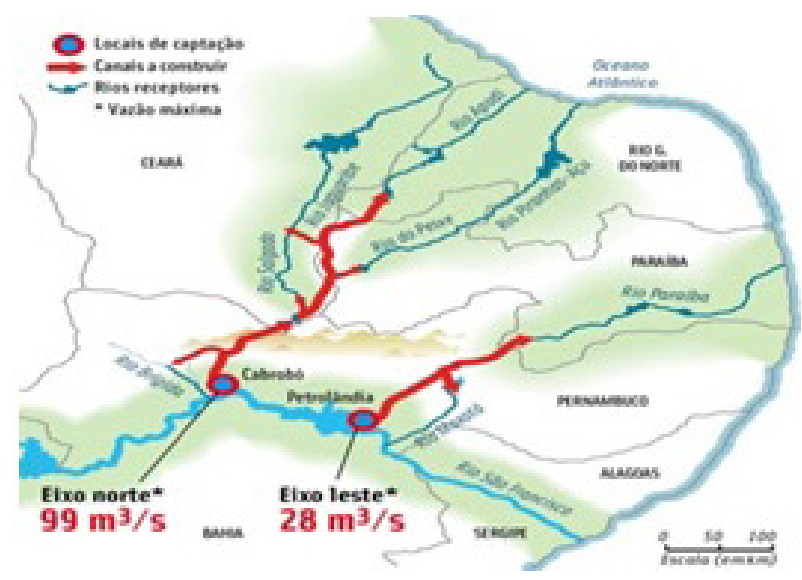

FIGURA 2 - Locais de captação e vazões correspondentes no rio São Francisco

Fonte: Brasil, 2015²

Atualmente, a condução das obras reflete atrasos substanciais, tendo em vista que a licença prévia desse empreendimento foi emitida em abril de 2005, e a de

${ }^{2}$ Ministério da Integração Nacional. Acesso em http://planetasustentavel. abril.com.br/imagem/sao-francisco-meio325x380.jpg instalação, em maio de 2007, como informa o IBAMA (2010). Registre-se o "retrabalho", pontual, realizado em alguns trechos de canais devido a problemas de descontinuidade das obras, por alguns períodos, nas quais as estruturas hidráulicas ficaram expostas às intempéries e sem o devido tratamento e manutenção. A atual execução física do empreendimento é de $83,4 \%$, conforme dados de janeiro de 2016 do Ministério da Integração Nacional.

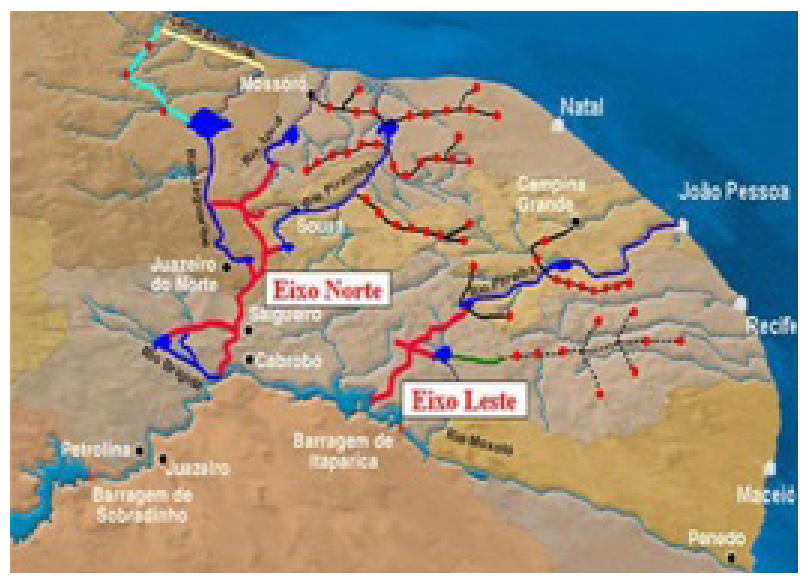

FIGURA 3 - Projeção da malha subsequente aos eixos da transposição e o Ramal do Agreste

Fonte: Brasil, 2015

O Governo Federal realizou testes nos motores de três Estações de Bombeamento (EB) do Projeto de Integração do Rio São Francisco: EBV-1 e EBV-2, no Eixo Leste, e a EBI-1, no Eixo Norte, conforme as Figuras 4 e 5. Para aperfeiçoar o gerenciamento, o Ministério da Integração Nacional (MIN) implantou, em 2011, um novo planejamento, com outro modelo de monitoramento, licitação e contratação para os seis trechos de obras (Metas $1 \mathrm{~N}, 2 \mathrm{~N}, 3 \mathrm{~N}, 1 \mathrm{~L}, 2 \mathrm{~L}$ e 3L). A nova previsão para conclusão das obras é dezembro de 2016.

\subsection{O Projeto Básico Ambiental e o Programa de Reassentamento de Populações}

Em torno de 12\% (R\$ 1 bilhão, aproximadamente) do orçamento do Projeto da Transposição (PISF) foi destinado à execução de programas básicos ambientais específicos que formam o Projeto Básico Ambiental (PBA), (BRASIL, 2005). Nessa estrutura, constam as

${ }^{3}$ Ministério da Integração Nacional. Acesso em http://4.bp.blogspot.com/CTODyi9MfCw/VcfDplw_uQI/AAAAAAAAYnw/hjJwMKRv9UA/s640/ transposicao_1.jpg.554×318_q85_crop.jpg 
medidas mitigadoras, compensatórias, de monitoramento e de controle ambiental que foram inicialmente dispostas em 36 programas ambientais, sendo posteriormente (2010) desdobradas em 38 programas (Figura 6), conforme as exigências emitidas pelo IBAMA, por ocasião da emissão da LICENÇA PRÉVIA LP 200/2005.

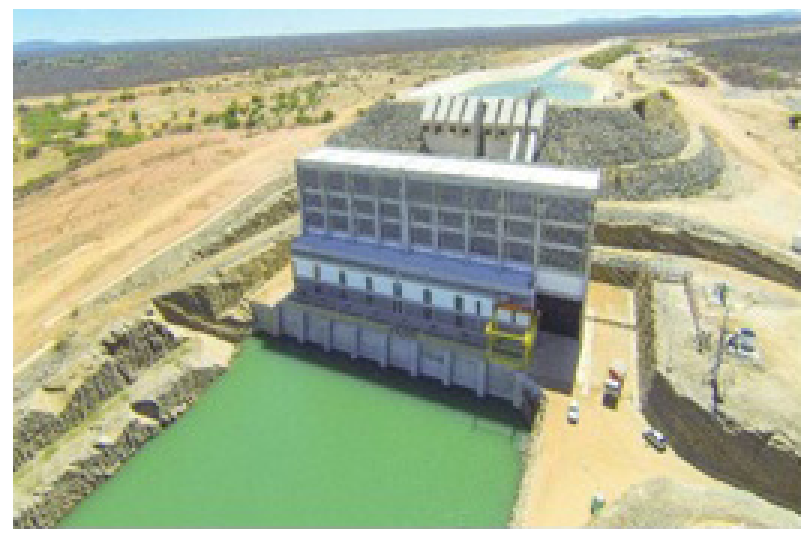

FIGURA 4 - Vista geral da Estação de Bombeamento EBI-1. Eixo norte

Fonte: Brasil, 2015

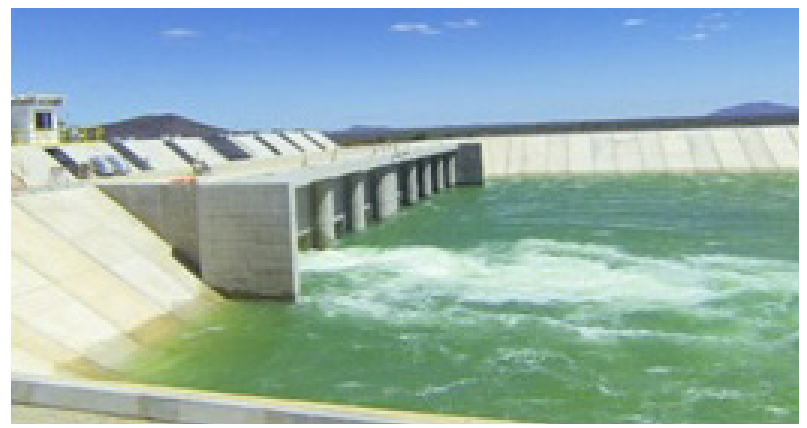

FIGURA 5 - Testes nos em canal

Fonte: Brasil, 2015

O Programa de Reassentamento de Populações (PBA 08) faz parte do atendimento exigido pelo IBAMA e contempla as medidas e ações que estão, no momento, sendo desenvolvidas junto às famílias que residiam nas áreas afetadas pelas obras, antes da implantação do projeto da transposição.

${ }^{4}$ Ministério da Integração Nacional. Acesso em http://www12.senado.gov. br/radio/1/noticia/2016-podera-ser-decisivo-p. radio.content.imagem/@@ images/55917a30-9540-40cc-aaee-7b5356148605.jpeg

${ }^{5}$ Ministério da Integração Nacional. Acesso em 22/08/2015 http://s2.glbimg.com/NQtbRO1XEmGRDYN0aOKCv_uR8TU=/620x465/s.glbimg. com/jo/g1/f/ori
A VPR Negreiros (Tabela 4) objeto deste estudo está inserida numa região representativa do bioma caatinga, que apresenta suas peculiaridades endêmicas quanto à fauna, flora e condições climáticas. Distante cerca de $9 \mathrm{~km}$ da sede da cidade de Salgueiro, a região de inserção dessa VPR, apresenta solos que são de modo geral, rasos e pedregosos, o que já serve de sinal de alerta à autossustentabilidade requerida à sua manutenção.

A VPR Negreiros é representativa das demais VPRs por possuir características naturais e sociais semelhantes. Das 18 Vilas Produtivas Rurais previstas, 15 delas já foram entregues às Famílias Reassentadas, que tem em comum o sonho de seguir em frente, apesar das mudanças que lhes foram impostas.

\subsection{A aplicação Î́ndice de Participação Social (IPS) na VPR Negreiros}

O Índice IPS permitiu correlacionar a participação social com os indicadores citados (Tabela 4) nas dimensões ambiental, social e econômica, e que são promotores de desenvolvimento da VPR Negreiros, a partir das informações verificadas nas Fases de Pré-Transferência e de Pós-Transferência das Famílias Reassentadas à VPR NEGREIROS, e que permitiu aglutinar as informações geradas, nesses momentos distintos, em um Quadro Comparativo do Índice de Participação Social (IPS), a partir de indicadores e atributos verificados na VPR Negreiros (Quadro 1).

Em que:

(*) Não fazia parte do questionário aplicado na fase de Pré-transferência.

(**) Não fazia parte do questionário aplicado na fase de Pós-transferência

Mesmo com a particularidade de que os questionários aplicados cada um em seu devido tempo, não foram exatamente os mesmos, foi possível inferir as analogias sem perda da fidelidade de análise, quanto à verificação das informações pertinentes às Dimensões Ambiental, Social e Econômica nos quais foram norteados, como corroborado por Januzzi (2005) e Souza (2008), ao abordarem essa temática complexa, mas passível de avaliação, a partir da ótica de atributos e indicadores relevantes à comunidade em geral, como no caso da participação das famílias nos processos que as conduzam notadamente a uma melhoria na qualidade de vida; processos esses avaliados conjuntamente em suas dimensões, e não em separado.

De acordo com essa análise, e aplicando-se a metodologia descrita na metodologia aplicada, A 


\begin{tabular}{|c|}
\hline $\begin{array}{c}\text { Programas de } \\
\text { Supervisão } \\
\text { e Controle de } \\
\text { Obras }\end{array}$ \\
\hline $\begin{array}{l}01 \text { - Plano de Gestão, } \\
\text { Supervisão e } \\
\text { Auditoria Ambiental }\end{array}$ \\
\hline $\begin{array}{l}02 \text { - Plano Ambiental } \\
\text { de Construção (PAC) }\end{array}$ \\
\hline $\begin{array}{l}05 \text { - Programa de } \\
\text { Treinamento e } \\
\text { Capacitação de } \\
\text { Técnicos da Obra em } \\
\text { Questões Ambientais }\end{array}$ \\
\hline $\begin{array}{l}09 \text { - Programa de } \\
\text { Recuperação de } \\
\text { Áreas Degradadas }\end{array}$ \\
\hline $\begin{array}{l}10 \text { - Programa de } \\
\text { Supressão da } \\
\text { Vegetação e Limpeza } \\
\text { dosReservatónios }\end{array}$ \\
\hline $\begin{array}{l}27 \text { - Programa de } \\
\text { Monitoramento de } \\
\text { Processos Erosivos }\end{array}$ \\
\hline $\begin{array}{l}34 \text { - Programa de } \\
\text { Relocação das } \\
\text { Infraestruturasa } \\
\text { serem afetadas pela } \\
\text { Implantação do } \\
\text { Empreendimento }\end{array}$ \\
\hline $\begin{array}{l}38 \text { - Programa de } \\
\text { Monitoramento, } \\
\text { previsão e controle de } \\
\text { incêndios florestais na } \\
\text { faixa de servidão }\end{array}$ \\
\hline
\end{tabular}

\begin{tabular}{|l|l|}
\multicolumn{1}{|c|}{$\begin{array}{c}\text { Programas de } \\
\text { Liberação } \\
\text { da Faixa de Obra }\end{array}$} & \multicolumn{1}{c|}{$\begin{array}{c}\text { Programas } \\
\text { Compensatórios }\end{array}$} \\
\begin{tabular}{|l|l|} 
O6 - Programa de \\
Identificação e \\
Salvamento de Bens \\
Arqueológicos
\end{tabular} & $\begin{array}{l}\text { 12-Programa de } \\
\text { Desenvolvimento das } \\
\text { Comunidades } \\
\text { Indigenas }\end{array}$ \\
\hline $\begin{array}{l}\text { O7 -Programa de } \\
\text { Indenização de Terras } \\
\text { e Benfeitorias }\end{array}$ & $\begin{array}{l}\text { 13-Programa de } \\
\text { Compensação } \\
\text { Ambiental }\end{array}$ \\
\hline $\begin{array}{l}\text { O8 - Programa de } \\
\text { Reassentamento de } \\
\text { Populações }\end{array}$ & $\begin{array}{l}\text { 17-Programa de } \\
\text { Apoio às } \\
\text { Comunidades } \\
\text { Quilombolas }\end{array}$ \\
\hline
\end{tabular}

35 - Programa de

Acompanhamento da

Situação dos

Processos Minerários

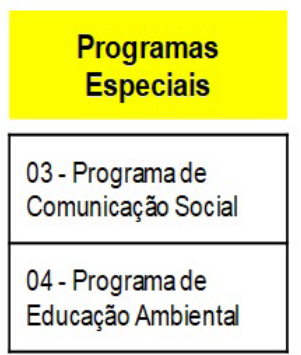

\section{Program as Ambientais}

\begin{tabular}{|l|}
\multicolumn{1}{|c|}{$\begin{array}{c}\text { Programas de Controle } \\
\text { e Monitoramento } \\
\text { Ambiental }\end{array}$} \\
\hline $\begin{array}{l}\text { 20-Programa de Monitoramento } \\
\text { de Vetores e Hospedeiros de } \\
\text { Doenças }\end{array}$ \\
\hline $\begin{array}{l}\text { 22-Programa de Monitoramento } \\
\text { da Qualidade da Água e } \\
\text { Limnologia }\end{array}$ \\
\hline $\begin{array}{l}\text { 23-Programa de Conservação } \\
\text { da Fauna e Flora }\end{array}$ \\
\hline $\begin{array}{l}37 \text { - Programa de Corte e Poda } \\
\text { seletiva da vegetação }\end{array}$ \\
\hline $\begin{array}{l}\text { 36-Programa de Monitoramento } \\
\text { da Cunha Salina }\end{array}$ \\
\hline
\end{tabular}

14 - Programa de Conservação e Uso do Entorno e das Águas dos Reservatórios

21 - Programa de Controle da Saúde Pública

25 - Programa de Monitoramento do Sistema Adutor e das Bacias Receptoras

28 - Programa de Monitoramento das Cargas Sólidas Aportantes nos Rios Receptores e seus Açudes Principais

33-Programa de Segurançae Alerta quanto às oscilações das vazões dos canais naturais que irão receber as águas transpostas

\begin{tabular}{|c|}
\hline $\begin{array}{l}\text { Programas } \\
\text { Estratégicos }\end{array}$ \\
\hline $\begin{array}{l}11 \text { - Programa de Apoio Técnico às } \\
\text { Prefeituras }\end{array}$ \\
\hline $\begin{array}{l}\text { 15- Programa de Implantação de } \\
\text { Infra-estrutura de Abastecimento } \\
\text { da Água às Populações ao Longo } \\
\text { dos canais }\end{array}$ \\
\hline $\begin{array}{l}19 \text { - Programa de Regularização } \\
\text { Fundiária nas Áreas do Entorno } \\
\text { dos Canais }\end{array}$ \\
\hline $\begin{array}{l}\text { 24- Programa de Prevenção à } \\
\text { Desertificação }\end{array}$ \\
\hline $\begin{array}{l}26 \text { - Programa de Cadastramento } \\
\text { de Fontes Hidricas Subterrâneas }\end{array}$ \\
\hline $\begin{array}{l}\text { 32- Programa de Apoio ao } \\
\text { Saneamento Básico }\end{array}$ \\
\hline $\begin{array}{l}16 \text { - Programa de Fornecimento d' } \\
\text { Água e Apoio Técnico para } \\
\text { Pequenas Atividades de Irrigação }\end{array}$ \\
\hline $\begin{array}{l}18 \text { - Programa de Apoio e } \\
\text { Fortalecimento dos Projetos de } \\
\text { Assentamentos Existentes }\end{array}$ \\
\hline $\begin{array}{l}30 \text { - Programa de Apoio às Ações } \\
\text { de Vigilância da Qualidade da Água } \\
\text { para } 0 \text { consumo humano }\end{array}$ \\
\hline $\begin{array}{l}31 \text { - Programa de Apoio à Redução } \\
\text { de perdas no sistema de } \\
\text { Abastecimento Público e Estímulo } \\
\text { ao Reuso da Água nas Bacias } \\
\text { Receptoras }\end{array}$ \\
\hline $\begin{array}{l}29 \text { - Programa de Apoio ao } \\
\text { Desenvolvimento deProjeto } \\
\text { Implantados, em Implantação e } \\
\text { Planejadosnas Bacias Receptoras }\end{array}$ \\
\hline
\end{tabular}

FIGURA 6 - Resumo dos Programas Ambientais do PISF Fonte: Brasil (2005b)

Dimensão Ambiental apontou resultados positivos ao compararem-se os momentos antes e depois da transferência dessas famílias.

Atributos analisados isoladamente como no caso da "Destinação de resíduo sólido" (coleta pública), Capacitações Gerais Previstas/Realizadas e Capacitações Ambientais Previstas/Realizadas, mostram isso, pelo fato desses atributos não ocorrerem quando as famílias moravam de modo difuso, o que foi diretamente refletido na Percepção e uso das Estruturas Socioambientais, que aferiu um IPS de 76,75\%, o que corresponde a uma categoria de nível de "PARTICIPAÇÃO
SATISFATÓRIA", na escala de participação social. O que se pode inferir pela não existência dessa percepção, no momento anterior à transferência, tendo em vista o modo difuso de localização em pequenos núcleos familiares, em que as famílias não possuíam estruturas socioambientais de uso comum, como possuem hoje; embora se destaquem os IPS de 76,39 e 84,72 $\%$, referidos à percepção anterior, quanto à preservação do meio ambiente, representados respectivamente, pela Caatinga e pelos Recursos hídricos, e que se enquadram e uma categoria de nível de "PARTICIPAÇÃO SATISFATÓRIA", na Escala de Participação Social. 
TABELA 4 - Relação das Vilas Produtivas Rurais - VPRs, do PISF

\begin{tabular}{|c|c|c|c|}
\hline VPR & Município & UF & $\begin{array}{l}\text { Total de } \\
\text { Famílias }\end{array}$ \\
\hline Captação & Cabrobó & $\mathrm{PE}$ & 17 \\
\hline Baixio dos Grandes & Cabrobó & PE & 83 \\
\hline Negreiros & Salgueiro & $\mathrm{PE}$ & 26 \\
\hline Uri & Salgueiro & PE & 45 \\
\hline Queimada Grande & Salgueiro & $\mathrm{PE}$ & 25 \\
\hline Malícia & Salgueiro & $\mathrm{PE}$ & 20 \\
\hline Pilões & Verdejante & $\mathrm{PE}$ & 25 \\
\hline Retiro & Penaforte & $\mathrm{CE}$ & 20 \\
\hline Ipê & Jati & $\mathrm{CE}$ & 20 \\
\hline Vassouras & Brejo Santo & $\mathrm{CE}$ & 145 \\
\hline Descanso & Mauriti & $\mathrm{CE}$ & 80 \\
\hline Bartolomeu & Cajazeiras & $\mathrm{PB}$ & 20 \\
\hline Quixeramobim & São José de Piranhas & $\mathrm{PB}$ & 46 \\
\hline Irapuá & São José de Piranhas & PB & 100 \\
\hline Jurema & São José de Piranhas & PB & 90 \\
\hline Zé Pedro & São José de Piranhas & PB & 10 \\
\hline Lafaete & Monteiro & $\mathrm{PB}$ & 15 \\
\hline Salão & Sertânia & PE & 38 \\
\hline TOTAL & & & 825 \\
\hline
\end{tabular}

Fonte: Brasil (2010)
Com a mesma analogia, a Dimensão Social, também apontou um quadro positivo de avanços quanto à participação familiar no processo de reassentamento; tendo-se que à satisfação quanto as Ações de Assistência Social, inferiram um IPS de $72 \%$, superior ao IPS de $29,16 \%$ anterior à transferência das famílias e que correspondia a uma categoria de nível de "PARTICIPAÇÃO INSUFICIENTE", na Escala de Participação Social, mas que foi enquadrada, após a transferência das famílias, ao nível de "PARTICIPAÇÃO SATISFATÓRIA".

Outro indicador que se pode inferir, referese à convivência entre as famílias, no momento anterior à transferência, que apresentou o IPS de $91,66 \%$, correspondendo a uma categoria de nível de "PARTICIPAÇÃO CONSOLIDADA", corroborando com o momento atual de convivência harmoniosa, verificado em campo, em que todos já se conheciam, além dos núcleos de parentesco existentes, o que facilitou, nas capacitações realizadas, em que se discutiram direitos e deveres junto às famílias e resultou na formação de um código de ética e convivência aplicável ao novo espaço formado.

O reflexo imediato dessa boa convivência aparece no Desempenho das Organizações Associativas, por meio do IPS de $80,55 \%$, no momento anterior à transferência das famílias, correspondendo a uma categoria de nível de "PARTICIPAÇÃO SATISFATÓRIA", como

QUADRO 1 - Comparativo do Índice de Participação Social (IPS), a partir de indicadores e atributos verificados na VPR Negreiros

\begin{tabular}{|c|c|c|}
\hline \multirow{2}{*}{ INDICADORES e ATRIBUTOS } & \multicolumn{2}{|c|}{ Período da Transferência à VPR NEGREIROS } \\
\hline & Anterior & Posterior \\
\hline DIMENSÃO AMBIENTAL & IPS (\%) & IPS $(\%)$ \\
\hline Percepção quanto à preservação da Caatinga & 76,39 & $* *$ \\
\hline Percepção quanto à preservação dos recursos hídricos & 84,72 & $* *$ \\
\hline Percepção e uso das estruturas socioambientais & $*$ & 76,75 \\
\hline DIMENSÃO SOCIAL & IPS $(\%)$ & IPS $(\%)$ \\
\hline Convivência na Comunidade & 91,66 & $* *$ \\
\hline Desempenho das Organizações Associativas & 80,55 & $* *$ \\
\hline Participação em ações comunitárias & 62,50 & $* *$ \\
\hline Satisfação quanto às Ações de Assistência Social & 29,16 & 72,00 \\
\hline Uso da Rede de Assistência Social & $*$ & 88,33 \\
\hline Percepção quanto ao atendimento à Saúde & * & 73,00 \\
\hline
\end{tabular}

Fonte: Elaborado pelo autor

(*) Não fazia parte do questionário aplicado na fase de Pré-transferência

(**) Não fazia parte do questionário aplicado na fase de Pós-transferência 
também quando relacionado ao verificado no IPS de 62,50 $\%$ quanto à Participação em Ações Comunitárias antes da transferência, o que correspondia a uma categoria de nível de "BAIXA PARTICIPAÇÃO", mas que foi devidamente superado pelo fato de que no momento $96 \%$ das famílias participam como associados das atividades realizadas atualmente, junto à Associação dos reassentados da Vila Produtiva Rural Negreiros (ARVIPRON).

Quanto ao Uso da Rede de Assistência Social, serviço esse ausente no momento anterior á transferência familiar, é apresentado um IPS de 88,33\% que corresponde a uma categoria de nível de "PARTICIPAÇÃO SATISFATÓRIA", mas com "tendência" de nível de PARTICIPAÇÃO CONSOLIDADA", se considerar-se a proximidade com o limite inicial desse nível que é IPS de 90 \% , na Escala de Participação Social.

Com relação à Percepção quanto ao atendimento à Saúde, o IPS de $73 \%$ foi aferido, o que corresponde a uma categoria de nível de "PARTICIPAÇÃO SATISFATÓRIA", refletindo um avanço, se compararmos o momento anterior em que as famílias dependiam de visitas esporádicas dos agentes de saúde municipal, ao passo que hoje se tem o funcionamento de um posto de saúde na própria VPR Negreiros.

Também importante, nesse contexto de participação social, a Dimensão Econômica, merece destaque no que diz respeito à renda daquelas famílias, de acordo com os resultados apresentados nas fases de Pré-Transferência e de Pós-Transferência das famílias reassentadas à VPR Negreiros. Chamou à atenção, o fato da composição da renda em si que apresentou grande dependência do trabalho informal, normalmente em atividades agropecuárias, sem nível de qualificação adequado às explorações, no modus de vida operante quando as famílias viviam ou isoladas ou em pequenos núcleos familiares, ao passo que após a Transferência à VPR, essa composição ficou a cargo dos Programas Sociais do Governo Federal, seguida da Previdência Social e das Aposentadorias, mas nada que sobreponha à importância atual da Verba de Manutenção Temporária (VMT), presente no cotidiano das famílias já há 06 anos.

A consequência dessa composição foi retratada na Renda Média Mensal familiar, aferida em valores correspondentes ao salário mínimo vigente em cada época, que foi de $\mathbf{0 , 8} \mathrm{SM}$ antes das transferências e evoluída para 1,9 SM após a instalação das famílias na VPR Negreiros.

Importante destacar que o núcleo habitacional onde ocorreu esse processo registrou um aumento populacional de 107 para 123 pessoas, desde a transferência das famílias, e que das 26 residências instaladas oficialmente, hoje tem mais 07 residências construídas por familiares nos lotes residenciais, o que reflete uma tendência positiva, quanto ao processo de reinserção socioeconômico e ambiental local.

\section{CONSIDERAÇÕES FINAIS}

$\mathrm{O}$ artigo apresentou a participação social como significativa à mudança na vida das famílias reassentadas na VPR Negreiros, no âmbito do Projeto São Francisco, sobretudo quando evidencia a importância dessa participação na melhoria da qualidade de vida das famílias reassentadas, em suas dimensões sociais, ambientais e até mesmo econômica.

No entanto, este estudo não se pretende concluso, pois na verdade carece de outros, em momentos adiante à conclusão do próprio Projeto da Transposição, mais aprofundados na busca pela sustentabilidade ambiental, tendo em vista que o "viés produtivo" necessita ser problematizado, para que aquelas famílias saiam do ciclo vicioso e pernicioso dos programas sociais, que embora sejam importantes nesse primeiro momento, como no caso da Verba de Manutenção Temporária (VMT), não podem se tornar permanentes, para que as famílias possam ter as suas produções agropecuárias implantadas e estabilizadas.

Fica aqui o desafio de que se realizem novos estudos no campo das 18 Vilas Produtivas Rurais implantadas, sobretudo quanto às áreas produtivas, pois até o momento dessa pesquisa, nenhuma área irrigada foi oficialmente entregue, de acordo com o planejamento dos planos de exploração para os lotes de sequeiro e irrigado, processo esse determinante para que essas "VILAS RURAIS" se tornem de fato "PRODUTIVAS" e suas famílias comecem, sobremaneira, a gerar de modo significativo a sua autossustentabilidade.

\section{REFERÊNCIAS}

BANCO CENTRAL DO BRASIL - BCB. Metas para inflação. Disponível em: <http://www.bcb.gov.br/pec/ relinf/normativos.asp >. Acesso em: agosto de 2014.

BANG, J., LEE, I., NOH, M., LIM, J., OH, H. Design and Implementation of a Smart Control System for Poultry Breeding's Optimal LED Environment. International Journal of Control and Automation, v. 7, n. 2, p. 99-108, 2014. 
BENSON, E. R., HOUGENTOGLER, D. P., MCGURK, J., HERRMAN, E., ALPHIN, R. L. Durability of incandescent, compact fluorescent and light emitting diode lamps in poultry conditions. Applied Engineering in Agriculture, v. 29, n. 1, p. 103-111, 2013.

BORILLE, R.; GARCIA, R. G.; ROYER, A. F.; SANTANA, M. R.; COLET, S.; NAAS, I. A.; CALDARA, F. R.; ALMEIDA PAZ, I. C. L.; ROSA, E. S.; CASTILHO, V. A. R. The use of light-emitting diodes (LED) in commercial layer production. Brazilian Journal of Poultry Science, v. 15 n. 2, p. 135-140, 2013.

BOURGET, C. M. An introduction to light-emitting diodes. Hort Science, v. 43, n. 7, p. 1944-1946, 2008.

BRASIL. Ministério de Minas e Energia. Portaria Interministerial $\mathbf{N}^{\mathbf{0}} \mathbf{1 . 0 0 7}$, de 31 de dezembro de 2010. Disponível em: <http://www.mme.gov.br/mme/galerias/ arquivos/legislacao/portaria_interminestral/Portaria MME-MCT-MDIC_n_1.007-2010.pdf $>$. Acesso em: $0 \overline{3}$ agosto 2014.

CAO, J.; WANG, Z.; DONG, Y.; ZHANG, Z.; LI, J.; LI, F.; CHEN, Y. Effect of combinations of monochromatic lights on growth and productive performance of broilers. Poultry Science, v. 91, n. 12, p. 3013-3018, 2012.

CHEN, Y.; CAO, J.; LIU, W.; WANG, Z.; XIE, D.; JIA, L. Green and blue monochromatic lights promote growth and development of broilers via stimulating 6 testosterone secretion and myofiber growth. Journal of Applied Poultry Research, Gainesville, v. 17, n.2, p. 211-218, 2008.

DEEP, A., SCHWEAN-LARDNER, K., CROWE, T. G., FANCHER, B. I., CLASSEN, H. L. Effect of light intensity on broiler production, processing characteristics, and welfare. Poultry science, v. 89, n. 11, p. 2326-2333, 2010.

GEWEHR, C. E., de FREITAS, H. J. Iluminação intermitente para poedeiras criadas em galpões abertos. Revista de Ciências Agroveterinárias, v. 6, n.1, p. 5462, 2007.

GITMAN, L. J. Princípios de Administração Financeira. 12 ed. São Paulo: Pearson Education - Br, 2010.

JORDAN, R. A., TAVARES, M. H. Análise de diferentes sistemas de iluminação para aviários de produção de ovos férteis. Revista Brasileira de Engenharia Agrícola e Ambiental, v. 9, n. 3, p. 420-423, 2005.

KE, Y. Y., LIU, W. J., WANG, Z. X., CHEN, Y. X. Effects of monochromatic light on quality properties and antioxidation of meat in broilers. Poultry science, v. 90, n. 11, p. 2632-2637, 2011.

LEWIS, P. D; MORRIS, T. R. Poultry and coloured light. World's Poultry Science Journal, v. 56, p. 189-207, 2000.

LIU, W., WANG, Z., CHEN, Y. Effects of monochromatic light on developmental changes in satellite cell population of pectoral muscle in broilers during early post hatch period. The Anatomical Record, v. 293, n. 8, p. 1315-1324, 2010.

MENDES, A. A. A cadeia avícola brasileira. In: MACARI, M; MENDES, A. A.; MENTEN, J. F.; NÄÄS, I. A. (Orgs.). Anais... Produção de Frangos de Corte. Campinas: FACTA, 2. ed. p. 1-12, 2014.

MENDES, A. S., PAIXÃO, S. J., RESTELATTO, R., MORELLO, G. M., de MOURA, D. J., POSSENTI, J. C. Performance and preference of broiler chickens exposed to different lighting sources. The Journal of Applied Poultry Research, v. 22, n. 1, p. 62-70, 2013.

MENDES, A. S., REFFATI, R., RESTELATTO, R., PAIXÃO, S. J. Vision and illumination in the modern poultry production. Revista Brasileira de Agrociência, v. 16 , n. $1 / 4$, p. 5-13, 2010.

NEWNAN, D. G. LAVELle, J. P. Fundamentos de Engenharia Econômica. Rio de Janeiro: LTC, 2000.

OLANREWAJU, H. A., THAXTON, J. P., DOZIER, W. A., PURSWELL, J., ROUSH, W. B., BRANTON, S. L. A review of lighting programs for broiler production. International Journal of Poultry Science, v. 5, 4, p. 301-308, 2006.

PRESCOTT, N. B.; WATHES, C. M. Spectral sensitivity of the domestic fowl (Gallus g. domesticus). British Poultry Science, v. 40, n. 3, p. 332-339, 1999.

PUCCINI, A. L. Matemática Financeira. 9. ed. São Paulo: Elsevier, 2011.

ROZENBOIM, I.; ROBINZON, B.; ROSENSTRAUCH, A. Effect of light source and regimen on growing broilers. British Poultry Science, v. 40, n. 4, p. 452-457, 1999. 
ROZENBOIM, I., BIRAN, I., CHAISEHA, Y., YAHAV, S., ROSENSTRAUCH, A., SKLAN, D., HALEVY, $\mathrm{O}$. The effect of a green and blue monochromatic light combination on broiler growth and development. Poultry Science, v. 83, n. 5, p. 842-845, 2004.

RUTZ, F.; SILVA, F. H. A.; NUNES, J. K. Fundamentos de um programa de luz para frangos de corte. In: MACARI, M; MENDES, A.A.; MENTEN, J. F.; NÄÄS, I. A. (Orgs.).

Anais... Produção de Frangos de Corte. Campinas: Facta, 2. ed. p. 225-250, 2014.

SANTANA, M. R. de, GARCIA, R. G., NÄÄS, I. A., Paz, IBIARA C. de L. A., CALDARA, F. R., BARRETO, B. Light emitting diode (LED) use in artificial lighting for broiler chicken production. Engenharia Agrícola, v. 34, n. 3, p. 422-427, 2014.
SHERWIN, C. M.; LEWIS, P. D.; PERRY, G. C. The effects of environmental enrichment and intermittent lighting on the behaviour and welfare of male domestic turkeys. Applied Animal Behaviour Science, v. 62, n. 4, p. 319-333, 1999.

UDDIN, S.; SHAREEF, H.; MOHAMED, A. Power quality performance of energy-efficient low-wattage LED lamps. Measurement, v. 46, n. 10, p. 3783-3795, 2013.

WATKINS, S. Poultry Lighting: LED Bulbs Provide Energy Savings and Durability. Division of Agriculture, Research \& Extension, University of Arkansas System, 2011. Disponível em: < http:// poultryscience.uark.edu/4474.php $>$. Acesso em: nov. 2013. 